\title{
O Hubble e a lucratividade dos bancos
}

\section{6 s bancos brasileiros têm lucros astronômicos". A fra- se parece conter uma daquelas verdades que se su- põem irretocáveis. Em conseqüência, como grande-} zas astronômicas exigem instrumentos igualmente astronômicos, os lucros dos bancos são examinados com telescópios de grande poder o Hubble, de preferência. Mas seria este o instrumento ideal? A simples substituição do modelo para aferição dos ganhos - do ROE (retorno sobre patrimônio líquido) pelo ROA (retorno sobre ativos) proporciona al gumas surpresas.

por David F. Hastings FGV-EAESP

Toda vez que o pensamento coletivo de nosso país se volta para a necessidade de aprimorar o desempenho econômico brasileiro, acena-se com a possibilidade de apertar 0 cinto em torno dos gordos lucros dos bancos.

Antes mesmo da discussão "esquentar", a revista Poder (fevereiro de 2002) observou que o lucro do Banco I taú não só é proporcionalmente bem mais elevado do que os das empresas brasileiras em geral, como também se mostra cerca de quatro vezes maior do que os de al guns dos mais destacados bancos globalizados. 0 artigo também salientou que a lucratividade da organização em questão é a maior dentre as instituições financeiras em operação no continente americano - do sul, do centro e do norte!

O bservações como essa têm circulado em outros meios 
de comunicação e têm estado presentes no debate público sobre 0 assunto. Nas entrelinhas, parece haver a sugestão de que, se os bancos sacrificassem parte de seus lucros, baixando as taxas de juros que cobram, por exemplo, a economia brasileira como um todo se beneficiaria e o país poderia chegar à equanimidade social.

Asqueixas parecem se agrupar em quatro categorias principais: 1) Os lucros dos bancos brasileiros são muito maiores do que os de instituições financeiras de outros países; 2) os lucros dos bancos são bem superiores aos de outras categorias de empresas; 3) os altos juros bancários comprometem outros setores; e 4) os ganhos dos banqueiros são maiores do que os dos demais empresários.

\section{Há a crença de que, se os bancos}

\section{sacrificassem parte de seus lucros,}

\section{a equanimidade social e econômica}

\section{se restabeleceria no Brasil.}

É claro que não se pretende negar o elevado grau de rentabilidade obtido por al guns bancos, tampouco o fato de que a redução nas taxas de juros - a exemplo do que vem sendo feito nos Estados Unidos - traria alívio significativo, em curto prazo, a muitos segmentos da sociedade brasileira. Mas é preciso fazer certos reparos a al gumas das interpretações que vêm circulando, para que a questão possa ser vista de uma forma mais clara.

Os bancos brasileiros diante de seus pares internacionais. Em primeiro lugar, no que diz respeito aos lucros dos bancos brasileiros em relação aos das instituições financeiras de outras partes do mundo, cabe lembrar que, como em qualquer atividadeempresarial, o retorno - lucro das organizações é em parte proporcional ao grau de risco a que estão expostas.

$N$ ão é nenhum segredo que nosso país se situa em patamar de risco bem superior aos das principais nações do hemisfério norte. Esse grau mais el evado de risco encontra expressão nos níveis das taxas básicas de juros: no Brasil, esta foi recentemente fixada em $18,5 \%$ ao ano, ante os aproximadamente $4 \%$ (ou menos) anuais dos Estados Unidos. Ou seja, nossa taxa básica é mais de quatro vezes superior à norteamericana. Esse dado por si só já justificaria o fato de alguns bancos brasileiros obterem lucros muito maiores do que os de seus congêneres norte-americanos.

Devemos somar a esse dado a circunstância de que, fixadas as taxas referenciais de acordo com o risco inerente ao próprio mercado, se algum banco redobrar seus cuidados na concessão de empréstimos, reduzindo assim seu nível individual de risco, essa instituição tenderá a beneficiar-se de taxas que, em certo sentido, são superiores às que seriam indicadas para seu perfil de risco. É evidente: qualquer empresa que se esforce para assegurar condições mais favoráveis do que a maioria, especialmente no que diz respeito a seus negócios, tende a ganhar mais do que a média das companhias comparáveis.

As instituições financeiras em relação a outras empresas. Em seguida, há a questão do grau de lucratividade dos bancos diante do que ganham empresas de outros setores. Cabe observar que, quando falamos em lucratividade, pensamos em uma medida relativa - ou seja, o lucro em relação a al guma coisa. Consolidou-se entre as empresas o hábito de associar o lucro ao capital investido, ao patrimônio líquido (é o modelo "ROE" - Return on Equity). 0 problema é que essa fórmula simplesmente não é válida se o objetivo é comparar a lucratividade dos bancos com os rendimentos de outros setores. Em empresas industriais e comerciais, o patrimônio líquido é uma medida razoável e grosseiramente homogênea da grandeza da companhia situação que não se aplica aos bancos.

A essência do negócio bancário é justamente administrar recursos de terceiros. Assim, se nas empresas industriais e comerciais a relação de recursos de terceiros para recursos próprios normal mente varia entre 1:1 e 2:1 - dito de modo bastante aproximado, pois há valores maiores ou menores dependendo do segmento - , essa mesma al avancagem pode chegar a 15:1, ou mais, nos bancos. Nessa situação, 0 patrimônio líquido de um banco não pode ser visto como medida de tamanho da mesma forma como é calculada em outros tipos de organizações. 
A questão da alavancagem dos bancos é regulada pela Resolução 2.099 do Banco Central do Brasil. Em linhas gerais, 0 limite operacional de um banco é inversamente proporcional ao nível de risco de seus ativos. Se uma instituição financeira concentrasse todos os seus ativos em categorias isentas de risco - por exemplo, títulos públicos federais -, estaria livre de qualquer limite sobre sua alavancagem. Por outro lado, um banco que concentra todos os seus ativos na categoria mais arriscada, não poderia ter mais do que nove vezes o valor de seu patrimônio líquido.

Para comparar a lucratividade de bancos com a de outras categorias de empresas, seria indicada a utilização de outro critério. Em vez de avaliar a eficiência pela ótica do retorno para os acionistas ou proprietários (ROE), a avaliação passaria a focalizar a eficiência das empresas pelo retorno obtido com base no total dos ativos - éo modelo "ROA" - Return on Assets - . Comparações feitas sob esse enfoque tendem a ser mais eqüitativas quando confrontamos diferentes setores.

Para testar essa hipótese, com o apoio do Centro de Excelência Bancária e do Centro de Estudos em Finanças, da FGV-EAESP, foram analisados dados dos balanços disponíveis no início do ano referentes a 350 empresas de 19 setores, incluindo os balanços de 18 instituições financeiras. Os resultados desse estudo dão sustentação, em linhas gerais, à seguinte proposição: a lucratividade dos bancos, pela abordagem tradicional do ROE (18,57\%), realmente é muito superior à da maioria dos outros setores; mas, pela abordagem proposta do ROA $(1,78 \%)$, revelase menor do que as de quase todos os demais setores (veja o Quadro abaixo).

\section{Quadro: ROE, ROA e alavancagem em diferentes setores econômicos}

\begin{tabular}{|l|c|c|c|c|}
\hline SETORES & EMPRESAS & ROE & ROA & ALAVANCAGEM \\
\hline Agropecuária, pesca, extrativismo e reflorestamento & 1 & $4,51 \%$ & $2,59 \%$ & 1,74 \\
\hline Bancos, seguradoras e serviços financeiros & 18 & $18,57 \%$ & $1,78 \%$ & 10,40 \\
\hline Comércio & 10 & $3,81 \%$ & $1,57 \%$ & 2,42 \\
\hline Construtoras & 13 & $-0,35 \%$ & $-0,12 \%$ & 2,82 \\
\hline Energia elétrica (geração, transmissão e distribuição) & 36 & $-0,42 \%$ & $-0,24 \%$ & 1,76 \\
\hline Indústrias de alimentos e bebidas & 22 & $7,60 \%$ & $3,65 \%$ & 2,08 \\
\hline Indústrias de computadores, equipamentos elétricos, & 14 & $-3,54 \%$ & $-1,58 \%$ & 2,24 \\
\hline eletrônicos e componentes & & & & \\
\hline Indústrias de máquinas industriais & 12 & $15,66 \%$ & $8,41 \%$ & 1,86 \\
\hline Indústrias de papel e celulose & 9 & $6,18 \%$ & $3,62 \%$ & 1,71 \\
\hline Indústrias de produção de minerais não metálicos (cimento, vidro etc.) & 6 & $10,15 \%$ & $7,84 \%$ & 1,30 \\
\hline Indústrias de produção química (petroquímicos, remédios, fertilizantes etc.) & 31 & $9,37 \%$ & $4,72 \%$ & 1,99 \\
\hline Indústrias de tecidos, roupas e calçados & 28 & $-0,99 \%$ & $-0,48 \%$ & 2,05 \\
\hline Indústrias de veículos e peças (carros, barcos, aviões etc.) & 20 & $25,72 \%$ & $7,91 \%$ & 3,25 \\
\hline Indústrias siderúrgicas e metalúrgicas & 35 & $4,67 \%$ & $1,86 \%$ & 2,51 \\
\hline Mineração (exceto petróleo e gás) & 3 & $20,48 \%$ & $10,18 \%$ & 2,01 \\
\hline Petróleo e gás natural (extração, refino e distribuição) & 7 & $31,76 \%$ & $13,43 \%$ & 2,36 \\
\hline Serviços de telecomunicações & 48 & $3,97 \%$ & $4,12 \%$ & 0,96 \\
\hline Serviços de transporte aéreo, aquático, rodoviário e ferroviário & 6 & $138,19 \%$ & $-13,60 \%$ & $-10,16$ \\
\hline Outros & 31 & $4,36 \%$ & $2,48 \%$ & 1,76 \\
\hline Totais e médias & 350 & $15,77 \%$ & $3,06 \%$ & 1,85 \\
\hline and & & & \\
\hline
\end{tabular}

(último balanço disponível em fevereiro de 2002) 
Nesse conjunto de dados, al guns setores talvez devessem ser desconsiderados por conterem quantidade muito pequena de empresas - é o caso da "Agropecuária" e, quem sabe da "Mineração"- ou por envolverem dados possivelmente atípicos - como "Energia Elétrica" e "Serviços de Transporte Aéreo", este com Resultado e Patrimônio Liquido negativos.

A análise do quadro permite conclusões interessantes: a) Se a lucratividade ROE dos bancos, de $18,57 \%$, é considerada elevada, o que dizer da rentabilidade das empresas de Petróleo, de 31,76\%; das de Veículos e Peças, de 25,72\%; das de Mineração, de 20,48\%; e, em menor escala, das de Máquinas Industriais, de 15,66\%? Todas representam setores de importância fundamental para a economia.

b) Esses mesmos setores apresentam lucratividade pela abordagem ROA muito maior do que a dos bancos, que ficou em 1,78\%: Petróleo, com 13,43\%; Veículos e Peças, com 7,91\%; M ineração, com 10,18\%; e Máquinas Industriais, com $8,41 \%$. ra mais objetiva, aos limites impostos pela regulamentação do mercado.

Os juros bancários e a felicidade geral da nação. Existe uma vontade na sociedade de que os bancos sacrifiquem um pouco de seus excelentes rendimentos em benefício da economia em geral, reduzindo as taxas dejuros que praticam.

$\mathrm{Na}$ apreciação dessa argumentação, é preciso lembrar que as taxas de juros são parte importante da política monetária do governo: juros altos estimulam o investimento e desestimulam o consumo, enquanto juros baixos desestimulam 0 investimento e estimulam o consumo. No contexto em que o país se encontra, são necessários investimentos produtivosem grande escalae, por outro lado, épreciso afastar a ameaça de um novo processo inflacionário, que poderia resultar da expansão exagerada do consumo.

Até muito recentemente, os aportes de investimentos estrangeiros no país ganhavam destaque na imprensa. Se gundo as manchetes, o Brasil seria um dos mercados mais atraentes para investimentos por parte das nações mais ricas. Essa exuberância em parte deve-se aos elevados níveis de juros praticados pelo governo. Mais recentemente, a divulgação da hipótese deuma brusca eacentuada redução nas taxas de juros teve 0 efeito imediato de deixar o país menos atraente: um caso típico de ação e reação.

c) Vários setores de base - por exemplo, Petróleo, Alimentação e Bebidas, Mineração, Química, Veículos e Peças, Papel e Celulose e Telecomunicações - exibem lucratividade ROA consideravelmente superior à dos bancos. Lembrando que o ROA representa uma medida do grau de eficiência com que uma empresa explora, em proveito próprio, o conjunto de recursos à sua disposição, segue que as empresas dessas áreas sabem tornar mais rentáveis os recursos disponíveis do que organizações de outros ramos de atividade, inclusive as do setor financeiro.

Todo administrador de empresas tem por obrigação otimizar o retorno para seus investidores, por meio da exploração dos recursos que tem à disposição. Deve se sujeitar, é claro, às balizas recomendadas pela ética e, de manei-
Mas resta, ainda, a desconfiança de que os bancos poderiam, afinal, reduzir seus juros. Se a hipótese for verdadeira, como então explicar o fato de que instituições financeiras globalizadas, imensamente mais poderosas do que suas concorrentes locais, praticam, em suas operações no Brasil, as mesmas taxas de juros que os bancos brasileiros? 0 fato ocorre apesar dessas mesmas instituições desejarem conquistar participações maiores no mercado nacional. Essa constatação talvez indique que as taxas atualmente praticadas se encontram em níveis adequados às circunstâncias. Seja como for, persiste a vontade de que os bancos reduzam os níveis de juros.

$\mathrm{N}$ ão faz muito tempo, o próprio presidente do Banco Itaú, Sr. Roberto Setúbal, à época também presidente da Febraban - Federação Brasileira das Associações de Bancos - , 
previu que, em poucos anos, os juros estariam rondando os $10 \%$ ao ano. Na época, o patamar encontrava-se na casa dos $40 \%$ anuais. Hoje, a $18,5 \%$, os juros caíram a menos da metade do que eram. Enquanto mostra que mais de dois terços do caminho previsto pelo Sr. Setúbal já foram percorridos, essa evolução também indica que o processo deve ser gradual.

Um lugar ao sol, mas com risco de chuvas. Por fim, ainda há a questão do retorno anormalmente elevado com que se premiam os acionistas dos bancos (ou, pelo menos, alguns deles).

Não há dúvida de que, em muitos casos, os retornos são muito elevados - a média da amostrade instituições financeiras apresentada no quadro comparativo é de 18,57\% - para esse propósito, a abordagem ROE é a aplicável -, embora não sejam os mais elevados.

Por outro lado, épreciso lembrar queos acionistas controladores de bancos se sujeitam a um risco a que os proprietários de outras categorias

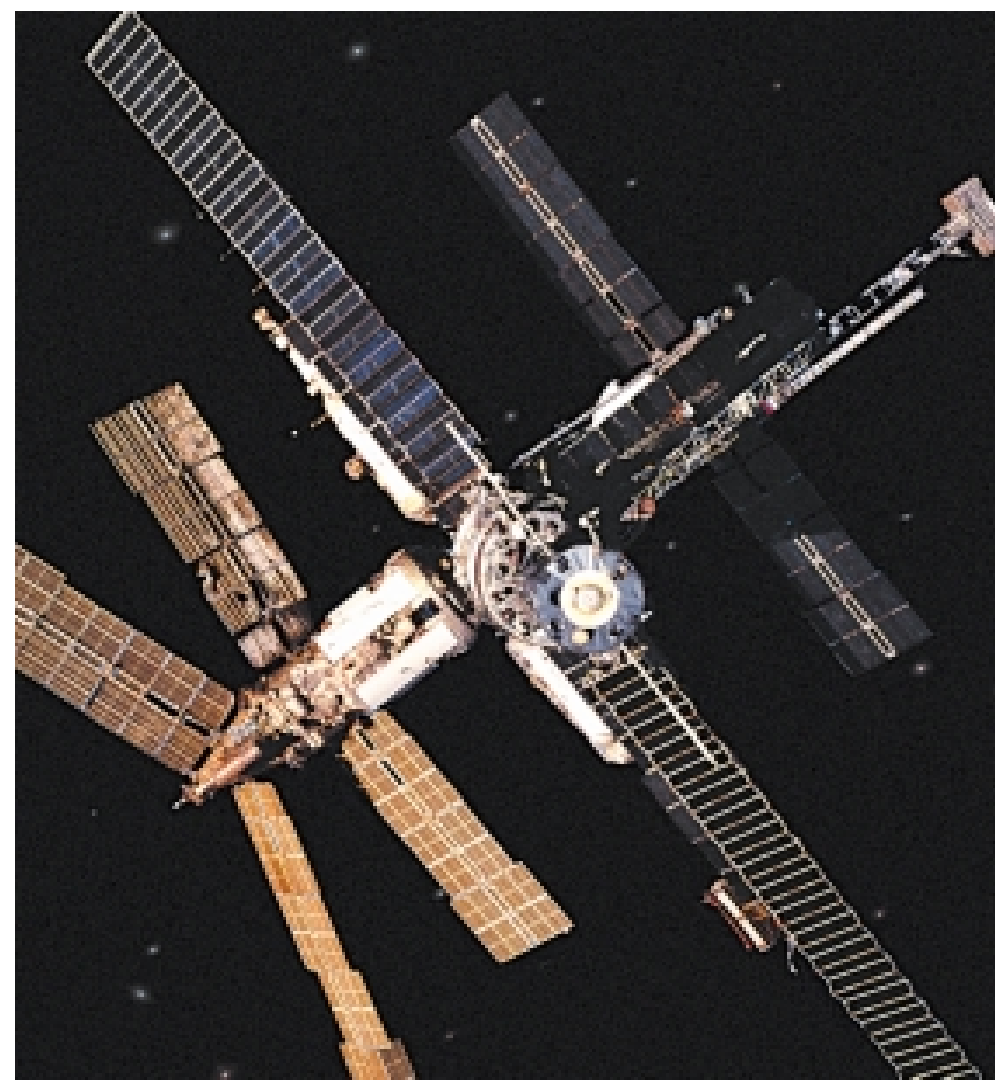
de empresa não se expõem: em caso de falência de organização não-bancária, os investidores se arriscam a perder os valores aplicados na empresa. O s responsáveis por bancos, por seu turno, não só se sujeitam a perder o capital investido na própria instituição, como também a ver seus bens pessoais arrestados. Esse risco adicional para a atividade bancária justifica, aos olhos de acionistas que investem na área, uma expectativa de retorno maior.

Conclusão - pesos e medidas. Como vimos, a crença generalizada deque os lucros dos bancos brasileiros são, quase quepor definição, anormalmenteelevados deve-se, em grande parte, ao uso de instrumentos ou referenciais inadequados para sua avaliação.

Primeiro, na comparação com instituições inseridas em outras realidades econômicas, as diferenças entre as distintas realidades devem ser levadas em conta - o patamar de juros no setor financeiro brasileiro é muito superior ao de outras economias mais sedimentadas.

Segundo, na comparação com organizações de outros

setores, dentro de uma mesma realidade econômica, a estrutura financeira típica das distintas áreas pode afetar drasticamente os resultados aparentes - ou seja, dada a enorme disparidade da al avancagem característica da atividade bancária em confronto com a de outras atividades, a lucratividade deve ser medida pelo retorno sobre ativos (ROA) e não pelo retorno sobre o patrimônio líquido (ROE).

Terceiro, um setor econômico não pode ser considerado culpado por operar dentro dos referenciais fixados pela dinâmica do mercado. Além disso, há fortes indícios de que os níveis de juros vigentes no Brasil são aqueles que o riscopaís exige.

Quarto, as comparações de remuneração ao capital realizadas de um setor para outro devem levar em conta os riscos inerentes a cada um deles - os banqueiros sujeitam-se a riscos maiores do que a maioria das outras categorias de empresários.

Assim, por mais extraordinário que possa parecer, o telescópio Hubble é total mente inadequado para bisbilhotar a vida do vizinho! 